\title{
NONFLORAL SOURCES OF CHEMICALS THAT ATTRACT MALE EUGLOSSINE BEES (APIDAE: EUGLOSSINI)
}

\author{
W. MARK WHITTEN, ALLEN M. YOUNG, and DAVID L. STERN
}

The above paper appeared in Volume 19, Number 12, pp. 3017-3027. Due to an inadvertent error, the incorrect figure printed as Figure 1 on p. 3020. The correct figure and caption are printed on the following page. 


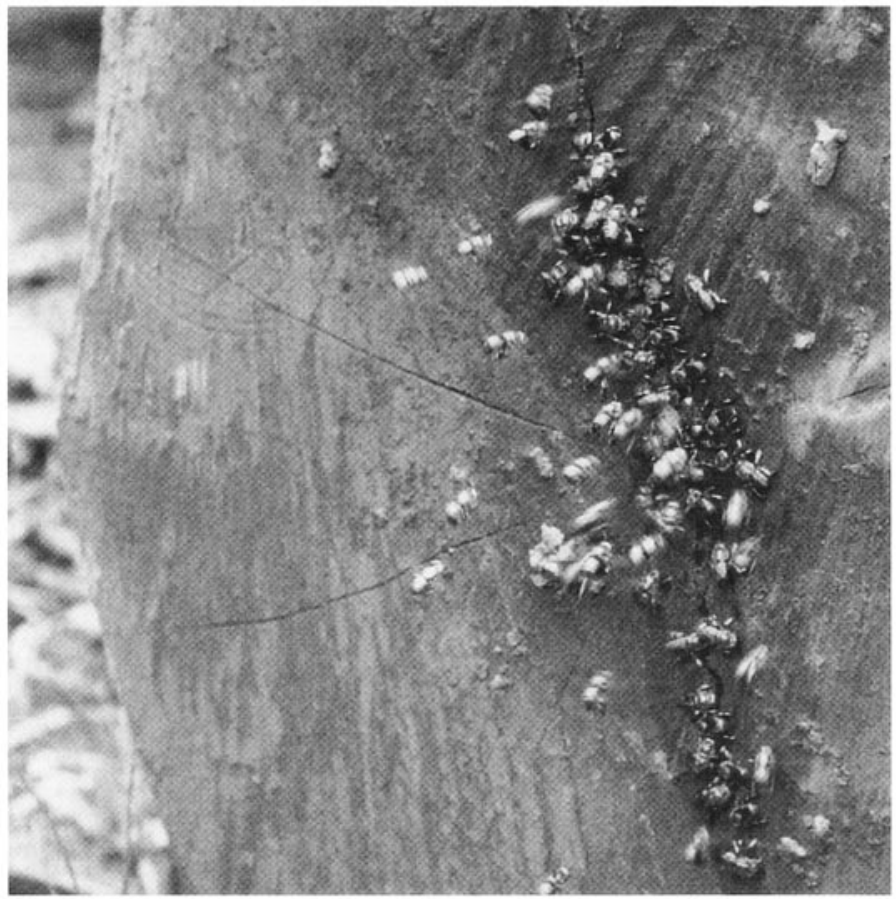

Fig. 1. Male Euglossa purpurea collecting volatiles from crack in sawn end of skatoleproducing Ocotea log in Sarapiqui District, Costa Rica. 